\title{
Carbon-isotope record of the Early Jurassic (Toarcian) Oceanic Anoxic Event from fossil wood and marine carbonate (Lusitanian Basin, Portugal)
}

\author{
Stephen P. Hesselbo ${ }^{a, *}$, Hugh C. Jenkyns ${ }^{a}$, Luis V. Duarte ${ }^{b}$, Luiz C.V. Oliveira ${ }^{c}$ \\ ${ }^{a}$ Department of Earth Sciences, University of Oxford, Parks Road, Oxford OX1 3PR, UK \\ ${ }^{\mathrm{b}}$ Departamento de Ciências da Terra, Centro de Geociências, Faculdade de Ciências e Tecnologia da Universidade de Coimbra, \\ 3000-272 Coimbra, Portugal \\ c Petrobras/Cenpes, Cidade Universitária, Ilha do Fundão, 21941-598, Rio de Janeiro, Brazil
}

Received 7 May 2006; received in revised form 1 November 2006; accepted 2 November 2006

Available online 13 December 2006

Editor: H. Elderfield

\begin{abstract}
The Toarcian Oceanic Anoxic Event (OAE) in the Early Jurassic ( 183 Ma ago) was characterized by widespread near-synchronous deposition of organic-rich shales in marine settings, as well as perturbations to several isotopic systems. Characteristically, two positive carbon-isotope excursions in a range of materials are separated by an abrupt negative shift. Carbon-isotope profiles from Toarcian fossil wood collected in England and Denmark have previously been shown to exhibit this large drop $\left(\sim-7 \%\right.$ in $\delta^{13} \mathrm{C}$ values, interpreted as due to an injection of isotopically light $\mathrm{CO}_{2}$ into the ocean-atmosphere system. However, the global nature of this excursion has been challenged on the basis of carbon-isotope data from nektonic marine molluscs (belemnites), which exhibit heavier than expected carbonisotope values. Here we present new data, principally from fossil wood and bulk carbonate collected at centimetre scale from a hemipelagic section at Peniche, coastal Portugal. This section is low in organic carbon (average TOC $=\sim 0.5 \%$ ), and the samples should not have suffered significant diagenetic contamination by organic carbon of marine origin. The carbon-isotope profile based on wood shows two positive excursions separated by a large and abrupt negative excursion, which parallels exactly the profile based on bulk carbonate samples from the same section, albeit with approximately twice the amplitude $(\sim-8 \%$ in wood versus $\sim-3.5 \%$ in carbonate). These data indicate that the negative carbon-isotope excursion affected the atmosphere and, by implication, the global ocean as well. The difference in amplitude between terrestrial organic and marine carbonate curves can be explained by greater water availability in the terrestrial environment during the negative excursion, for which there is independent evidence from marine osmiumisotope records and, plausibly, changes in atmospheric $\mathrm{CO}_{2}$ content, for which independent evidence is also available. The Peniche succession is also notable for the occurrence of re-deposited sediments: their lowest occurrence coincides with the base of the negative excursion and their highest occurrence coincides with its top. Thus, slope instability and sediment supply could have been strongly linked to the global environmental perturbation, an association that may misleadingly simulate the effects of sea-level fall.

(C) 2006 Elsevier B.V. All rights reserved.
\end{abstract}

Keywords: carbon isotope; fossil wood; carbonate; Jurassic; Oceanic Anoxic Event

\footnotetext{
* Corresponding author.

E-mail address: stephen.hesselbo@earth.ox.ac.uk (S.P. Hesselbo).
} 